\title{
Fluorescence in situ hybridization investigation of cutaneous lesions in acute promyelocytic leukemia
}

\author{
Joanna E Wrede, Uma Sundram, Sabine Kohler, Athena M Cherry, Daniel A Arber \\ and Tracy I George
}

Department of Pathology, Stanford University School of Medicine, Stanford, CA, USA

\begin{abstract}
Cutaneous manifestations of acute promyelocytic leukemia are rare but well documented. Skin biopsies of leukemia can be difficult to confirm using morphology alone, and paraffin section immunophenotyping is not specific in separating acute promyelocytic leukemia from other acute myeloid leukemias involving the skin or inflammatory conditions, such as Sweet's syndrome and all-trans retinoic acid-associated genital ulcers, which may mimic leukemia cutis. Fluorescence in situ hybridization has been shown to be a fast and effective method of detecting the PML/RARA fusion gene characteristic of acute promyelocytic leukemia in fresh blood and bone marrow samples. Fluorescence in situ hybridization has also been demonstrated to be effective in detecting other chromosomal rearrangements in paraffin-embedded tissue. This retrospective study of cutaneous lesions from four patients with acute promyelocytic leukemia evaluates the utility of performing fluorescence in situ hybridization to confirm the presence of cutaneous manifestations of acute promyelocytic leukemia in formalinfixed, paraffin-embedded skin biopsies. All patients had previous bone marrow findings of acute promyelocytic leukemia with characteristic morphology, immunophenotype, and cytogenetic studies, which detailed the presence of the $t(15 ; 17)(q 22 ; q 12)$ rearrangement. Two skin biopsies showed an infiltrate of blastic cells involving the dermis in a diffuse pattern and one biopsy had a perivascular/periadnexal pattern. The fourth case, involving the scrotum, showed a predominant neutrophilic infiltrate diffusely involving the dermis and epidermis with a subset of blastic cells. Nuclei were extracted from core biopsies of the formalin-fixed paraffinembedded tissue and fluorescence in situ hybridization was performed using a dual color, dual fusion $P M L$ RARA probe. All cases showed evidence of the $t(15 ; 17)$ rearrangement, with $90,79,51$ and $16 \%$ positive signal patterns, each well above background limits. Fluorescence in situ hybridization appears to be a robust technique to detect cutaneous manifestations of acute promyelocytic leukemia in formalin-fixed paraffinembedded skin biopsies.
\end{abstract}

Modern Pathology (2005) 18, 1569-1576. doi:10.1038/modpathol.3800465; published online 29 July 2005

Keywords: acute promyelocytic leukemia; leukemia cutis; fluorescence in situ hybridization; $P M L / R A R A$; all-trans retinoic acid, paraffin-embedded tissue

Acute promyelocytic leukemia is defined by the World Health Organization as an acute myeloid leukemia in which abnormal promyelocytes predominate with the $\mathrm{t}(15 ; 17)(\mathrm{q} 22 ; \mathrm{q} 12)$ chromosomal rearrangement and variants involving $17 \mathrm{q} 2-12 .^{1,2}$ Acute promyelocytic leukemia is also known as AML-M3 using the French-American-British classification. This rearrangement causes the retinoic acid receptor alpha $(R A R A)$ gene on $17 \mathrm{q} 12$ to fuse with a nuclear regulatory factor on 15q22 (promye-

Correspondence: Dr TI George, MD, Stanford University Medical Center, Department of Pathology, 300 Pasteur Drive, Room H1501B, Stanford, CA 94305-5627, USA.

E-mail: tigeorge@stanford.edu

Received 23 May 2005; revised and accepted 24 June 2005; published online 29 July 2005 locytic leukemia or $P M L$ gene) giving rise to the PML/RARA gene fusion product. ${ }^{2-4}$ Distinguishing acute promyelocytic leukemia from other forms of acute leukemia is particularly important given its favorable response to all-trans retinoic acid (ATRA) therapy, the high risk of disseminated intravascular coagulation, and the better prognosis of this type of acute leukemia. $^{5}$

Extramedullary disease is rare in patients with acute promyelocytic leukemia, with the skin being the most commonly affected site and accounting for over one-third of the reported cases. ${ }^{6}$ It has been suggested that cutaneous cases of extramedullary disease in acute promyelocytic leukemia may have a characteristic predilection to occur at sites of puncture for blood and bone marrow samples and that treatment with ATRA may predispose these 
patients to extramedullary relapse. ${ }^{7,8}$ We believe that fluorescence in situ hybridization (FISH) provides an efficient and reliable method of detecting the $t(15 ; 17)$ rearrangement associated with acute promyelocytic leukemia in suspected cases of leukemia cutis, and will aid in distinguishing cutaneous involvement by acute promyelocytic leukemia from reactive processes or other neoplastic processes that can occur in this setting.

\section{Materials and methods}

\section{Patient Samples and Controls}

Records from the Stanford University Medical Center, Department of Pathology were reviewed for patients with a history of acute promyelocytic leukemia who underwent skin biopsies to rule out cutaneous involvement in the years 1995-2004. Four samples were identified with adequate tissue available, all in the form of formalin-fixed paraffinembedded tissue. Hematoxylin and eosin-stained slides were reviewed, as were any immunohistochemical studies that had been previously performed using standard methods. Diagnostic bone marrow biopsies, flow cytometry studies, and cytogenetic studies were also reviewed on all patients.

Positive controls included a formalin-fixed, paraffin-embedded biopsy of a scalp lesion from a patient with acute promyelocytic leukemia previously confirmed to contain the $\mathrm{t}(15 ; 17)$ rearrangement by FISH of enzymatically disaggregated fresh tissue, and a bone marrow sample from the same patient showing acute promyelocytic leukemia confirmed to contain the $t(15 ; 17)$ rearrangement by classical cytogenetics. Negative controls included paraffin-embedded samples both of skin from a patient with lichenoid dermatitis and tonsil obtained from a patient with reactive follicular hyperplasia.

\section{Fluorescence In Situ Hybridization}

Samples were prepared in a variation of the protocol described by Paternoster et al. ${ }^{9}$ In this procedure, hematoxylin and eosin-stained slides corresponding to tissue blocks were examined to locate areas of cellular infiltrates. One to three cores were then extracted from the tissue blocks in these preidentified areas using a 20-gauge blunt tip needle (MicroTools, Vacaville, CA, USA). This tissue was deparaffinized by soaking $10 \mathrm{~min}$ each in three changes of $100 \mu \mathrm{l}$ xylene, followed by rehydration in 95,75 and $50 \%$ ethanol. Tissue was then disaggregated using the tip of a large fresh paperclip and digested in proteinase $K$ solution $(0.005 \%$ proteinase $K$, $30 \mathrm{U} / \mathrm{mg}$ protein, in $0.05 \mathrm{~mol} / \mathrm{l}$ tris hydroxymethyl aminomethane hydrochloride ( $\mathrm{pH} 7.0), 0.01 \mathrm{~mol} / \mathrm{l}$ ethylenediaminetetraacetic disodium salt, and
$0.01 \mathrm{~mol} / \mathrm{l}$ sodium chloride) for $30 \mathrm{~min}$ at $37^{\circ} \mathrm{C}$. The nuclei were washed with phosphate-buffered saline, then washed and resuspended in $100 \mu \mathrm{l}$ Carnoy's fixative (75\% methanol, $25 \%$ acetic acid). Approximately $8 \mu \mathrm{l}$ of suspension were applied to each microscope slide (SIP Superfrost Plus Microscope Slides, Allegiance Healthcare Corporation, MacGaw Park, IL, USA) within a $12 \mathrm{~mm}$ circle. Nuclei were dried onto the slide for $15 \mathrm{~min}$ at $65^{\circ} \mathrm{C}$. Slides were then pretreated using a Vysis VP $2000^{\mathrm{TM}}$ processor (Vysis, Downers Grove, IL, USA). Settings included: (1) $20 \mathrm{~min}$ in room temperature $0.2 \mathrm{~N}$ hydrochloric acid, (2) distilled water $\left(\mathrm{dH}_{2} \mathrm{O}\right)$ rinse, (3) $30 \mathrm{~min}$ in $80^{\circ} \mathrm{C}$ Vysis pretreatment reagent (\#30801250), (4) $\mathrm{dH}_{2} \mathrm{O}$ rinse, (5) $10 \mathrm{~min}$ in $37^{\circ} \mathrm{C}$ protease I (10\% pepsin), (6) $\mathrm{dH}_{2} \mathrm{O}$ rinse, (7) $10 \mathrm{~min}$ in room temperature $10 \%$ buffered formalin, (8) $\mathrm{dH}_{2} \mathrm{O}$ rinse, (9) dehydration in room temperature ethanol series, and (10) air dry. The PML/RARA dual color, dual fusion probe (Vysis) was applied in a dilution of $0.5 \mu \mathrm{l}$ probe $+1.0 \mu \mathrm{l}$ water $+3.5 \mu \mathrm{l}$ LSI buffer, for a total of $5 \mu \mathrm{l}$ probe mix per slide. Slides were covered with $18 \mathrm{~mm}$ diameter circular coverslips (VWR Scientific, West Chester, PA, USA) and sealed with rubber cement, then placed in a HYBrite ${ }^{\mathrm{TM}}$ hybridization instrument (Vysis), denatured $8 \mathrm{~min}$ at $80^{\circ} \mathrm{C}$ and hybridized overnight (at least $16 \mathrm{~h}$ ) at $37^{\circ} \mathrm{C}$. Slides were then washed for $2 \mathrm{~min}$ in $0.4 \times$ saline sodium citrate (SSC) $/ 0.3 \%$ Nonidet P-40 (NP-40) (Vysis) at $73^{\circ} \mathrm{C}$ and 5-60 s in room temperature $2 \times$ SSC/0.1\% NP-40. Slides were air-dried and counterstained with 4',6-diamidino-2-phenylindole (DAPI III) (Vysis).

Hybridized slides were analyzed by a single microscopist using the CytoVision 3.0 Genus ${ }^{\mathrm{TM}}$ capture system (Applied Imaging, San Jose, CA, USA) with an Olympus BX51 fluorescent microscope (Olympus America, Melville, NY, USA) utilizing a $\times 100$ oil immersion objective and 82000 and 83000 series triple pass filter sets (Chroma Technology Corp., Rockingham, VT, USA). Only intact, nonoverlapping nuclei were considered scorable. Fusion signals were defined as red and green signals that were either directly adjacent (less than one signal width apart) or overlapping. Using these criteria, two sets of 100 consecutive interphase nuclei were examined for the number of green (G), red (R), and fusion (F) signals, resulting in a total of 200 nuclei reviewed for each sample. A nucleus was considered negative for the PML/RARA fusion product if it contained two red $P M L$ signals and two green RARA signals (2R2G), and positive if it contained a dual fusion signal pattern (1R1G2F) (Figure 2). Background levels of signal patterns were determined by scoring a total of 1000 negative control tonsil nuclei. The maximum range of abnormal signals (ie, 1R1G2F) per 200 nuclei plus 2 standard deviations (s.d.) was calculated as the background level of abnormal signals for negative control samples. Hence, a case was considered to demonstrate a PML/RARA gene 
rearrangement if the percentage of nuclei with the 1R1G2F pattern was above this threshold (maximum range +2 s.d.).

\section{Results}

\section{Clinical and Pathologic Data}

Patient age ranged from 15 months to 46 years of age including two males and two females. Clinical details are summarized in Table 1. The patients were each previously diagnosed with acute promyelocytic leukemia on the basis of a bone marrow aspirate and biopsy. Cytogenetic studies, WrightGiemsa-stained aspirates and peripheral blood smears, hematoxylin and eosin-stained biopsies, and flow cytometry immunophenotypic studies of each case were reviewed to confirm the original findings. All patients had diagnostic bone marrow biopsies with the characteristic proliferation of abnormal promyelocytes (either hypergranular or hypogranular variants) with folded and indented nuclei, and cells containing frequent Auer rods. The typical flow cytometry immunophenotype was present with strong myeloperoxidase, myeloid markers CD13, CD33, CD117, variable CD34 expression and lack of HLA-DR. All diagnostic bone marrows had classical cytogenetics containing $\mathrm{t}(15 ; 17)(\mathrm{q} 22 ; \mathrm{q} 12)$.

All patients were treated with ATRA and standard induction chemotherapy (idarubicin, idarubicin/ cytarabine or daunorubicin/cytarabine), followed by consolidation chemotherapy (ATRA, idarubucin or daunarubicin/ATRA), with three of four patients achieving remission. Case 2, less than 1 month after induction therapy, developed neutropenic fever with multiple skin nodules, bilateral pulmonary infiltrates with multiple nodules, lip and tongue ulcers, with blood cultures positive only for coagulase-negative Staphylococcus, and all other fungal and viral cultures negative. While continuing to receive ATRA, he developed ulcerative scrotal papules (Figure 1). He was transferred to the intensive care unit with persistent fevers and pulmonary comprise requiring mechanical ventilation, hemodynamic support, and broad-spectrum antibiotics; he developed multiorgan failure and support was withdrawn. Case 1 relapsed with extramedullary disease 7 years after initial remission, followed 8 months later by a $3 \mathrm{~cm}$ umbilical mass (Figure 1) without bone marrow disease. Case 3 had three relapses with scalp lesions (Figure 1 from second relapse) and positive bone marrows, including relapse after autologous stem cell transplant, but remains in third complete remission after a matched sibling donor cord blood transplant. Case 4 relapsed in the central nervous system 6 months after remission followed by breast and scalp lesions, as well as bone marrow involvement. She subsequently relapsed again in the central nervous system following autologous bone marrow transplant and presented less than 1 year later with a $2.5 \mathrm{~cm}$ skin nodule on the abdomen (Figure 1). Following a third central nervous system relapse, she was transferred to hospice care.

\section{Morphology of Skin Biopsies}

Morphologic features are summarized in Table 2 and illustrated in Figure 1. Cases 1 and 4 showed similar histologic features, including a dense and diffuse monotonous proliferation of large blastic cells within the dermis, prominent Grenz zones and sparing of

Table 1 Summary of clinical features and FISH results for patients with acute promyelocytic leukemia and suspected leukemia cutis

\begin{tabular}{|c|c|c|c|c|c|c|c|c|}
\hline Case & $A g e^{\mathrm{a}} / \operatorname{sex}$ & $\begin{array}{l}\text { Site of skin } \\
\text { lesion }\end{array}$ & $\begin{array}{l}\text { Interval } \\
(\mathrm{m})^{\mathrm{b}}\end{array}$ & $B M^{\mathrm{c}}$ & Other sites EMD & Therapy for EMD & $\begin{array}{l}\text { PML/RARA } \\
\text { FISH (\%) }\end{array}$ & Outcome \\
\hline 1 & $46 y / M$ & Umbilicus & 85 & Neg & $\begin{array}{l}\text { Intracanicular, soft tissue } \\
\text { and lymph node }\end{array}$ & Radiation, arsenic & 79 & $\mathrm{~A} / \mathrm{R}$ \\
\hline 2 & $37 \mathrm{y} / \mathrm{M}$ & Scrotum & 1 & $\operatorname{Pos}^{\mathrm{e}}$ & Neg & None $^{\mathrm{f}}$ & 51 & $\mathrm{D}$ \\
\hline 3 & $15 \mathrm{~m} / \mathrm{F}$ & Scalp & 6 & Pos & Neg & $\begin{array}{l}\text { Arsenic, autoSCT, } \\
\text { radiation, alloSCT }\end{array}$ & 16 & $\mathrm{~A} / \mathrm{R}$ \\
\hline 4 & $24 \mathrm{y} / \mathrm{F}$ & Abdomen & 58 & $\mathrm{Neg}^{\mathrm{g}}$ & CNS, breast, scalp & $\begin{array}{l}\text { Intrathecal chemo, } \\
\text { arsenic, radiation, } \\
\text { autoSCT }\end{array}$ & 90 & $\mathrm{D}$ \\
\hline
\end{tabular}

$\mathrm{M}=$ male, $\mathrm{F}=$ female; Neg=negative; Pos = positive; EMD = extramedullary disease; autoSCT =autologous stem cell transplant; alloSCT = allogeneic stem cell transplant from matched sibling; FISH = percent of nuclei with 1R1G2F signal pattern indicating PML/RARA fusion product; $\mathrm{D}=$ deceased; $\mathrm{A}=$ alive; $\mathrm{R}=$ remission.

${ }^{\mathrm{a}}$ Age at time of initial diagnosis of acute promyelocytic leukemia; $\mathrm{y}=$ years; $\mathrm{m}=$ months.

${ }^{\mathrm{b}}$ Interval is the time in months between initial diagnosis and skin biopsy.

${ }^{\mathrm{c}}$ Bone marrow involvement by leukemia at the time of skin biopsy.

${ }^{\mathrm{d}} 8$ months prior to umbilical lesion, the patient had a C2-C6 intracanicular soft tissue mass compressing the spinal cord with a contiguous paraspinal mass and lymph node.

e Initial bone marrow showed acute promyelocytic leukemia and scrotal lesion was biopsied 1 month later.

${ }^{\mathrm{f}}$ Support was withdrawn as patient was in multiorgan failure.

gPrevious bone marrow biopsy 3 months before skin biopsy showed no evidence of leukemia. 
a
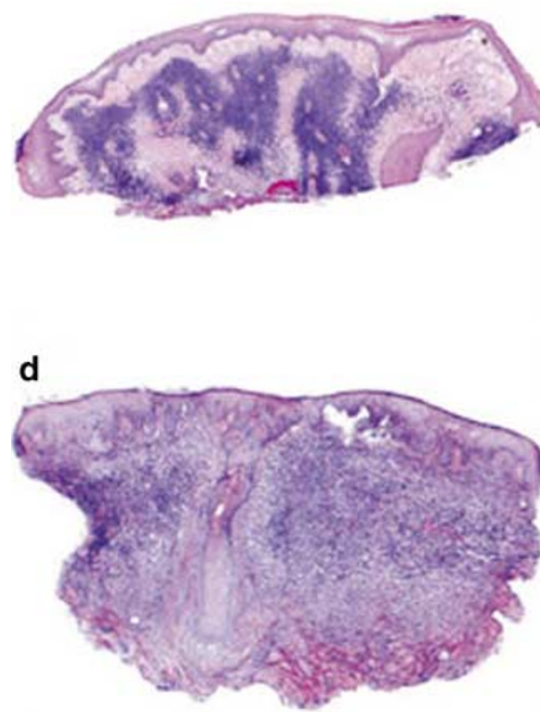

g
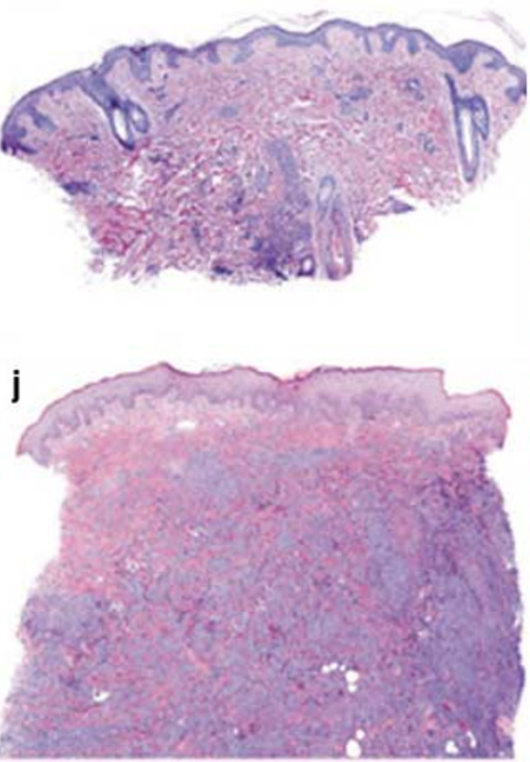
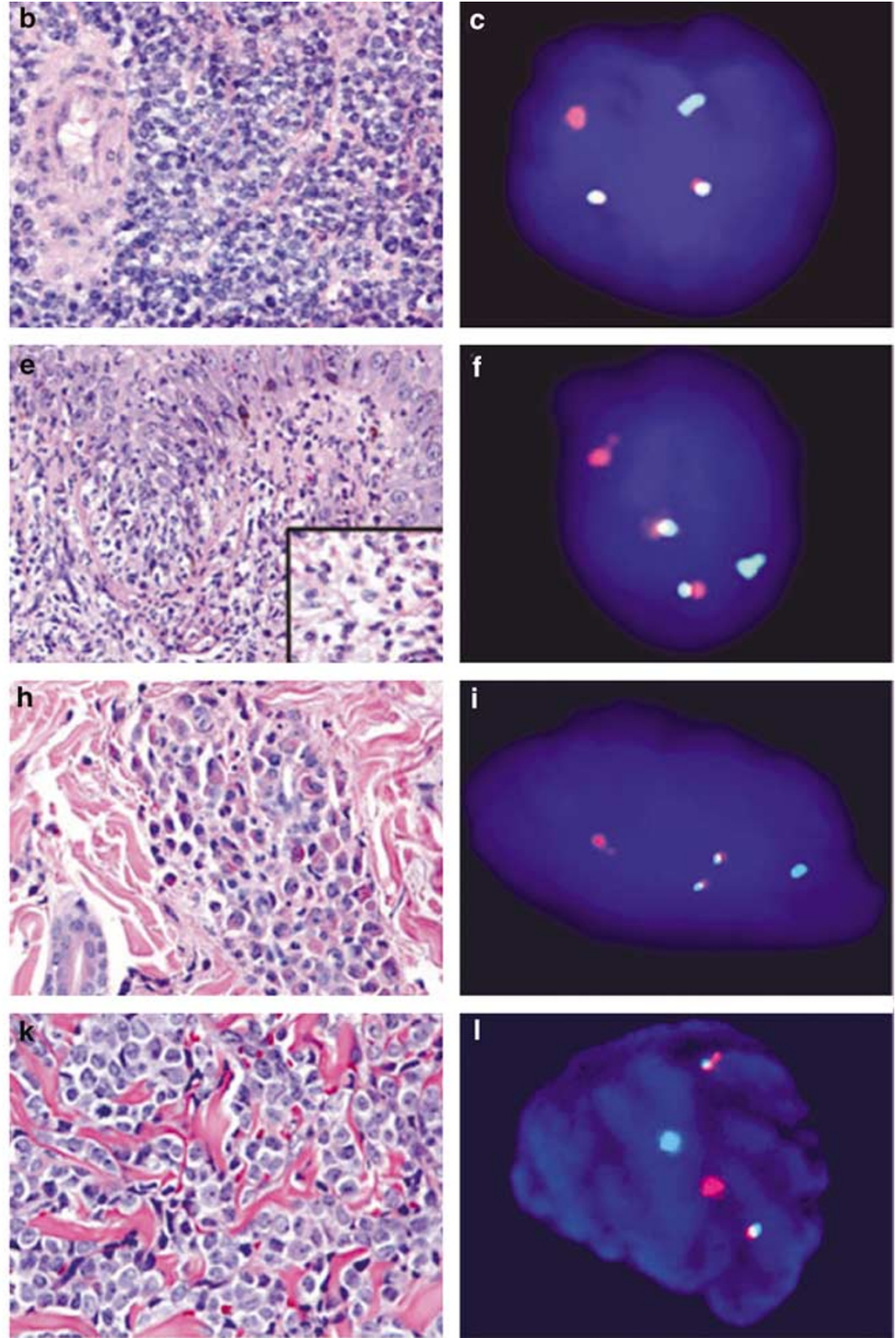

Figure 1 Case 1 (a-c). Sections from the umbilical skin biopsy (a) show a dense dermal proliferation of mononuclear cells with immature chromatin surrounded by edematous stroma. Epidermis is spared $(\mathrm{H} \& \mathrm{E}, \times 10)$. Frequent mitotic figures were noted at high power $(\mathbf{b}$, H\&E, $\times 400$ ). Representative nuclei from case 1 hybridized with dual color, dual fusion PML/RARA translocation probe. The two fusion signals indicate the fusion products PML/RARA and RARA/PML, while the separate red and green signals represent nonrearranged loci (c). Case 2 (d-f). Scrotal biopsy sections show a dense dermal infiltrate extending into the overlying epidermis (d, H\&E, $\times 10)$. The infiltrate consists of segmented neutrophils admixed with a population of immature cells containing bilobed forms (inset) (e, H\&E, $\times 400$ ). Representative nuclei from case 2 illustrating the 1R1G2F signal pattern indicative of t(15;17) (f). Case 3 (g-i). Sections from a scalp biopsy show a perivascular infiltrate extending deep into the dermis (g, H\&E, $\times 10)$. The cells contain abundant cytoplasm with eosinophilic granules. Nuclei are convoluted with occasional bilobed forms with fine chromatin and nucleoli (h, H\&E, $\times 400)$. FISH results were $16 \%$ positive for the $1 \mathrm{R} 1 \mathrm{G} 2 \mathrm{~F}$ signal pattern indicative of $\mathrm{t}(15 ; 17)$ as shown in representative nuclei (i). Case $4(\mathbf{j}-\mathbf{l})$. Skin sections from an abdominal nodule show a deep diffuse dermal infiltrate which spares the epidermis $(\mathbf{j}, \mathrm{H} \& \mathrm{E}, \times 10)$. Nuclei are large with fine chromatin and 1-2 small, distinct nucleoli with occasional irregular nuclear contours and frequent mitoses $(\mathbf{k}, \mathrm{H} \& \mathrm{E}, \times 400)$. A positive FISH signal pattern is illustrated with representative nuclei from case 4 (l).

the epidermis. The cellular infiltrates were comprised of immature mononuclear cells with twisted nuclei, smooth chromatin, 1-2 nucleoli and occasional bilobed forms. Granularity was not apparent in the blasts. Mitoses were frequent and apoptotic cells were also scattered throughout the infiltrate. The dermis in case 1 was more edematous and the overlying epidermis was spongiotic with focal 
parakeratosis admixed with bacteria; rare neutrophils were also present within the upper dermis. The scalp biopsy from case 3 showed a different histologic pattern with a perivascular and periadnexal infiltrate, including a prominent perineural component which was within the superficial dermis. The epidermis was also spared. In contrast to the blasts seen in cases 1 and 4, the cellular infiltrate from case 3 contained large immature cells with abundant granular cytoplasm. Many of the nuclei also appeared twisted and occasional bilobed forms were also noted. A smaller infiltrate of neutrophils was admixed with these blastic cells. The scrotal lesion from case 2 was markedly different in its morphology. Histologic sections showed focally ulcerated skin with a diffuse and dense infiltrate occupying the dermis and extending into the epidermis. The infiltrate consists predominantly of neutrophils admixed with a smaller population of large mononuclear cells with irregular nuclear outlines, fine chromatin and 1-2 nucleoli. Many of the neutrophils contained an eosinophilic granular cytoplasm. We did not observe necrosis as described in the majority of the ATRA-associated scrotal ulcerations. ${ }^{11-18}$ The histologic appearance was more reminiscent of Sweet's syndrome with the exception of the blastic infiltrate admixed with the more numerous neutrophils.

\section{Interphase FISH Analysis}

All four experimental samples yielded positive results above the background level for the $P M L /$ RARA fusion product, with percentages of $1 \mathrm{R} 1 \mathrm{G} 2 \mathrm{~F}$ signal patterns of 79, 51, 16 and $90 \%$ for cases $1,2,3$ and 4, respectively (Table 1, Figure 1). Review of negative control slides (Figure 2) revealed a back-

Table 2 Morphologic features of cutaneous lesions

\begin{tabular}{lllcccc}
\hline Case & $\begin{array}{l}\text { Site of skin } \\
\text { biopsy }\end{array}$ & Pattern & $\begin{array}{c}\text { Monomorphic } \\
\text { blastic infiltrate }\end{array}$ & Bilobed cells & $\begin{array}{c}\text { Granular } \\
\text { cytoplasm }\end{array}$ & $\begin{array}{c}\text { Admixed } \\
\text { neutrophils }\end{array}$ \\
\hline 1 & Umbilicus & Diffuse & Yes & Yes & No & No \\
2 & Scrotum & Diffuse & No & Yes & Yes $^{\text {a }}$ & Yes \\
3 & Scalp & Perivascular, & Yes & Yes & Nos & No \\
4 & Abdomen & periadnexal & Yes & Yes & No & \\
\hline
\end{tabular}

${ }^{\mathrm{a}}$ In contrast to the other cases where the infiltrate is primarily confined to the dermis, in case 2 the infiltrate diffusely involves the epidermis and dermis. The majority of the infiltrate is comprised of neutrophils, many with an eosinophilic granular cytoplasm, admixed with a smaller number of large blastic cells favored to represent differentiating promyelocytes.
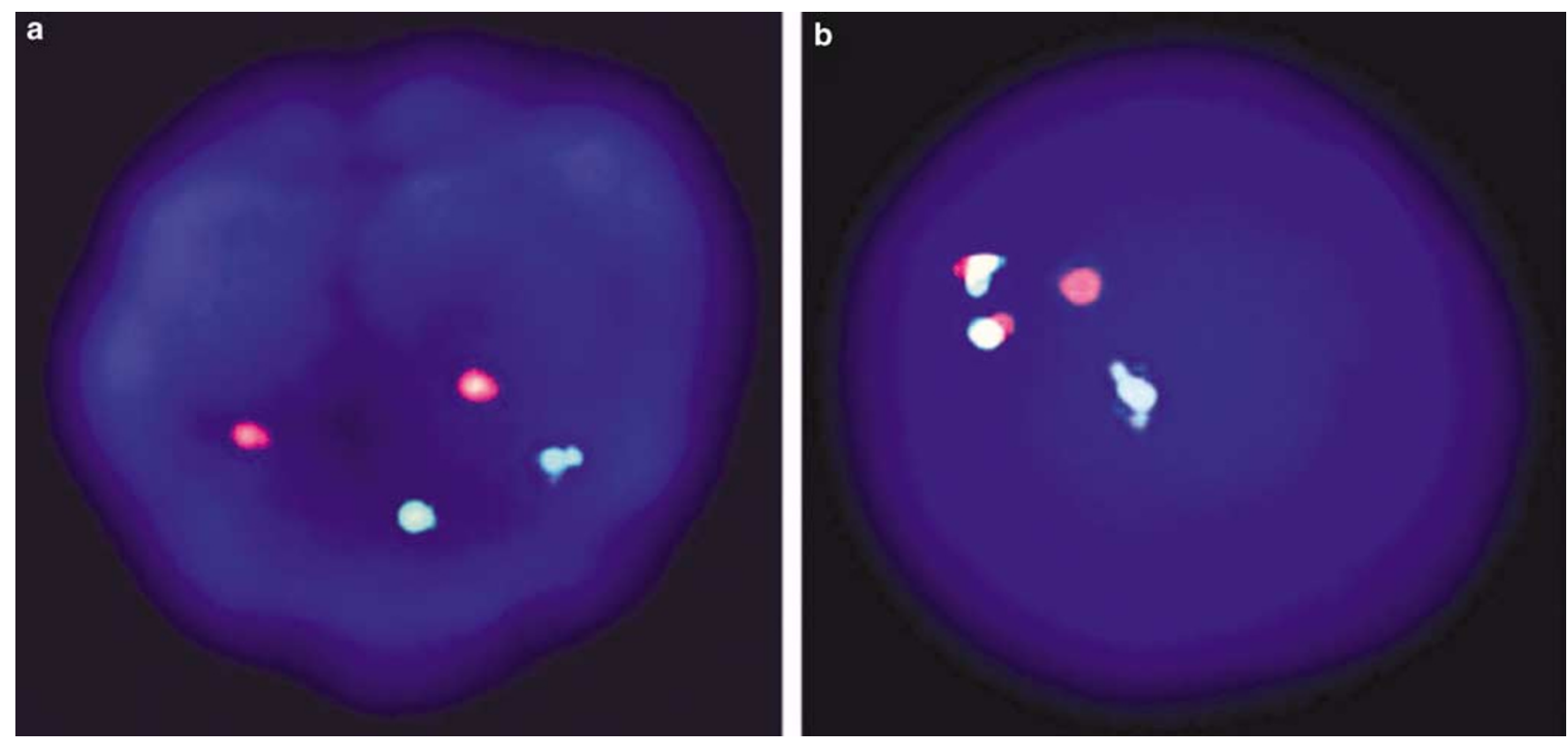

Figure 2 (a) Representative nuclei from reactive tonsil hybridized with dual color, dual fusion PML/RARA translocation probe. Two separate red and green signals indicate lack of rearrangement of chromosomes 15q32 and 17q12 (b). Representative nuclei from the positive skin control hybridized with dual color, dual fusion PML/RARA translocation probe. A positive FISH signal pattern (1R1G2F) is illustrated. 
ground level (maximum range of positive signals per 200 nuclei plus two standard deviations) of $3.3 \%$ 1R1G2F signal pattern. In contrast, the positive control from the skin biopsy (Figure 2) showed $61.5 \% 1 \mathrm{R} 1 \mathrm{G} 2 \mathrm{~F}$ and the positive bone marrow control had $48 \%$ 1R1G2F.

\section{Discussion}

The $t(15 ; 17)(q 22 ; q 12)$ chromosomal rearrangement associated with acute promyelocytic leukemia has been detected in the past by classical cytogenetics, PCR, and FISH of cultured bone marrow aspirate or peripheral blood cells. Skin biopsies, as those obtained to rule out leukemia cutis, are difficult to culture and are often immediately formalin-fixed for histological analysis, limiting the feasibility of techniques requiring fresh tissue. The ability to perform FISH analysis on formalin-fixed, paraffinembedded tissue can increase the ease and feasibility of identifying cytogenetic aberrations associated with leukemia cutis, such as the $t(15 ; 17)$ rearrangement.

In this study, we analyzed a series of four cases of possible leukemia cutis identified following treatment for acute promyelocytic leukemia. All cases were shown to contain the PML/RARA gene fusion product characteristic of acute promyelocytic leukemia through analysis by FISH utilizing a commercially available probe. Previous studies have shown this PML/RARA dual color, dual fusion translocation probe to perform well on peripheral blood and bone marrow samples, with a sensitivity of $98 \%$ and specificity of $100 \%$, and have suggested that this method can detect $\mathrm{t}(15 ; 17)(\mathrm{q} 22 ; \mathrm{q} 12)$, all variant forms of this translocation associated with $P M L$ and RARA, and all alternate translocations involving RARA and not $P M L .{ }^{18}$ Our evidence suggests that this probe is convenient and effective in evaluating formalin-fixed, paraffin-embedded tissue, like that most often available after skin biopsy of potential leukemia cutis.

Patients with acute promyelocytic leukemia undergoing induction therapy with ATRA can develop infections, drug-related conditions, Sweet's syndrome, and ATRA-related genital ulcerations, which can morphologically mimic leukemia. Sweet's syndrome, an acute febrile neutrophilic dermatosis, has been reported in patients with acute promyelocytic leukemia after ATRA therapy and is characterized by fever, neutrophilia, painful ulcer-like plaques, and rapid response to steroid therapy. ${ }^{19-29}$ This is often linked to or followed by the retinoic acid syndrome, a distinct clinical syndrome reported in up to one-quarter of patients treated with ATRA characterized by fever, dyspnea, hypotension, pleural or pericardial effusions and weight gain. ${ }^{30}$ ATRA-associated genital ulcerations, ${ }^{11-18}$ and ATRA-associated vasculitis ${ }^{31}$ and myositis ${ }^{32}$ have also been described in patients with acute promye- locytic leukemia. The painless genital ulcerations associated with ATRA therapy resolve after ATRA is discontinued.

While each of these entities appears to be clinically distinct from leukemia cutis, they can histologically mimic acute promyelocytic leukemia as they are composed of dermal sheets of maturing neutrophils. Sweet's syndrome is a neutrophilic infiltrate in the dermis without leukocytoclastic vasculitis. Histologic features of ATRA-associated genital ulcers include ulceration with dermal sheets of neutrophils and focal necrosis. Sweet's syndrome, the retinoic acid syndrome and ATRA-associated genital ulcers share several features including fever, neutrophilic infiltrate and improvement with steroids. However, Sweet's syndrome is primarily limited to the skin, with or without muscle involvement, and only rarely involves internal organs; ${ }^{27}$ the genital ulcers associated with ATRA are similarly limited to the genital area, most frequently described in the scrotum of men. ${ }^{11-18} \mathrm{In}$ contrast, the retinoic acid syndrome is marked by features of capillary leakage with systemic inflammation and infiltration into internal organs,${ }^{30}$ resulting in systemic symptoms typically occurring 2-21 days after onset of ATRA therapy. ATRA-associated Sweet's syndrome and the retinoic acid syndrome can occur together ${ }^{19}$ or rarely, Sweet's syndrome may precede the retinoic acid syndrome. ${ }^{22}$ Piette et $a l^{33}$ report a case of Sweet's syndrome associated with a myeloblastic infiltrate that mimicked leukemia cutis, but otherwise the clinical features were typical of Sweet's syndrome. In this case, the histology eventually showed the expected mature dermal infiltrate as the peripheral blood and bone marrow showed neutrophilic differentiation in response to ATRA. In a series of four patients described by Fukuno et al, ${ }^{17}$ histologic sections from one patient's testicular ulcer showed atypical granulocytes infiltrating the genital ulcer and in the vessel lumen, suggesting to these authors that the genital ulcers are due to infiltration of differentiated acute promyelocytic leukemia cells rather than a direct effect of ATRA. ${ }^{17}$ We found similar histologic findings in case 2, who presented with neutropenic fever and ulcerative papules on the scrotum while receiving ATRA, with a subset of cells resembling abnormal promyelocytes including rare bilobed forms; $51 \%$ of cells in this biopsy contained $P M L /$ RARA by FISH. These reports suggest that differentiating abnormal promyelocytes can undergo margination and recruitment to the skin to induce cutaneous lesions. Furthermore, the neutrophilic infiltrate seen in ATRA-associated skin lesions may be positive for $t(15 ; 17)$ if differentiating abnormal promyelocytes are present. This raises the question of whether ATRA-associated skin lesions represent a distinct clinical presentation of leukemia cutis or a drug effect. If residual differentiating promyelocytes are present in the inflammatory component one could argue that this favors partially treated 
leukemia cutis. One can also ask if there are thresholds of positivity for PML/RARA that correlate with leukemia cutis vs drug effect, assuming that the latter contains differentiating promyelocytes. In our study, we found a wide range of FISH positivity, from 16 to $90 \%$, associated with leukemia cutis. Further work remains to be carried out on drug effects seen in acute promyelocytic leukemia to address this question.

In summary, FISH appears to be a robust technique to detect cutaneous manifestations of acute promyelocytic leukemia in formalin-fixed, paraffinembedded skin biopsies, and this method may be useful in evaluating specimens that are not amenable to obtaining fresh tissue that is required for other approaches.

\section{Acknowledgements}

We thank Caroline Tudor for her help with the figures. Joanna E Wrede's work in this project was supported in part by the Stanford Medical Scholars Program.

\section{References}

1 Brunning RD, Matutes E, Flandrin G, et al. Acute myeloid leukaemia with recurrent genetic abnormalities. In: Jaffe ES, Harris NL, Stein H, Vardiman JW (eds). Tumours of Haematopoietic and Lymphoid Tissues. IARC Press: Lyon, France, 2001, pp 81-87.

2 Caligiuri MA, Strout MP, Gilliland DG. Molecular biology of acute myeloid leukemia. Semin Oncol 1997;24:32-44.

3 de The H, Chomienne C, Lanotte $\mathrm{M}$, et al. The $\mathrm{t}(15 ; 17)$ translocation of acute promyelocytic leukaemia fuses the retinoic acid receptor alpha gene to a novel transcribed locus. Nature 1990;347:558-561.

4 Melnick A, Licht JD. Deconstructing a disease: RARalpha, its fusion partners, and their roles in the pathogenesis of acute promyelocytic leukemia. Blood 1999;93:3167-3215.

5 Falanga A, Rickles FR. Pathogenesis and management of the bleeding diathesis in acute promyelocytic leukaemia. Best Pract Res Clin Haematol 2003;16: 463-482.

6 Rives S, Camos M, Bosch F, et al. Central nervous system involvement in acute promyelocytic leukemia. A description of two cases and review of the literature. Haematologica 1999;84:473-474.

7 Sanz MA, Larrea L, Sanz GF, et al. Cutaneous promyelocytic sarcoma at sites of vascular access and marrow aspiration. A characteristic localization of chloromas in acute promyelocytic leukemia? Haematologica 2000;85:758-762.

8 Wiernik PH, De Bellis R, Muxi P, et al. Extramedullary acute promyelocytic leukemia. Cancer 1996;78: 2510-2514.

9 Paternoster SF, Brockman SR, McClure RF, et al. A new method to extract nuclei from paraffin-embedded tissue to study lymphomas using interphase fluores- cence in situ hybridization. Am J Pathol 2002;160: 1967-1972.

10 Esser AC, Nossa R, Shoji T, et al. All-trans-retinoic acid-induced scrotal ulcerations in a patient with acute promyelocytic leukemia. J Am Acad Dermatol 2000;43:316-317.

11 Simzar S, Rotunda AM, Craft N. Scrotal ulceration as a consequence of all-trans-retinoic acid (ATRA) for the treatment of acute promyelocytic leukemia. J Drugs Dermatol 2005;4:231-232.

12 Mourad YA, Jabr F, Salem Z. Scrotal ulceration induced by all-trans retinoic acid in a patient with acute promyelocytic leukemia. Int J Dermatol 2005;44: 68-69.

13 Gettinger S, Shapira I, Scheinfeld N, et al. Complications of therapy in cancer patients: case 2. Scrotal ulceration during all-trans-retinoic acid therapy for acute promyelocytic leukemia. J Clin Oncol 2004;22: 4648-4649.

14 Paydas S. Scrotal ulceration associated with ATRA. Am J Hematol 2004;77:206-207.

15 Pavithran K, Arjun R, Aruna R, et al. Scrotal ulceration during induction therapy of acute promyelocytic leukemia with ATRA. Am J Hematol 2004;75: 260-261.

16 Fukuno K, Tsurumi H, Goto $\mathrm{H}$, et al. Genital ulcers during treatment with ALL-trans retinoic acid for acute promyelocytic leukemia. Leu Lymphoma 2003;44:2009-2013.

17 Charles KS, Kanaa M, Winfield DA, et al. Scrotal ulceration during all-trans retinoic (ATRA) therapy for acute promyelocytic leukaemia. Clin Lab Haematol 2000;22:171-174.

18 Brockman SR, Paternoster SF, Ketterling RP, et al. New highly sensitive fluorescence in situ hybridization method to detect PML/RARA fusion in acute promyelocytic leukemia. Cancer Genet Cytogenet 2003;145: 144-151.

19 Astudillo L, Loche F, Reynish W, et al. Sweet's syndrome associated with retinoic acid syndrome in a patient with promyelocytic leukemia. Ann Hematol 2002;81:111-114.

20 Park CJ, Bae YD, Choi JY, et al. Sweet's syndrome during treatment of acute promyelocytic leukemia with all-trans retinoic acid. Korean J Intern Med 2001; 16:218-221.

21 Al-Saad K, Khanani MF, Naqvi A, et al. Sweet syndrome developing during treatment with all-trans retinoic acid in a child with acute myelogenous leukemia. J Pediatr Hematol Oncol 2004;26:197-199.

22 Takada S, Matumoto K, Sakura T, et al. Sweet's syndrome followed by retinoic acid syndrome during the treatment of acute promyelocytic leukemia with all-trans retinoic acid. Int J Hematol 1999;70: 26-29.

23 Levi I, Raanani P, Shalmon B, et al. Acute neutrophilic dermatosis induced by all-trans retinoic acid treatment for acute promyelocytic leukemia. Leuk Lymphoma 1999;34:401-404.

24 Arun B, Berberian B, Azumi N, et al. Sweet's syndrome during treatment with all-trans retinoic acid in a patient with acute promyelocytic leukemia. Leuk Lymphoma 1998;31:613-615.

25 Hatake K, Uwai M, Ohtsuki T, et al. Rare but important adverse effects of all-trans retinoic acid in acute promyelocytic leukemia and their management. Int J Hematol 1997;66:13-19. 
26 Christ E, Linka A, Jacky E, et al. Sweet's syndrome involving the musculoskeletal system during treatment of promyelocytic leukemia with all-trans retinoic acid. Leukemia 1996;10:731-734.

27 Shirono K, Kiyofuji C, Tsuda H. Sweet's syndrome in a patient with acute promyelocytic leukemia during treatment with all-trans retinoic acid. Int J Hematol 1995;62:183-187.

28 Tomas JF, Escudero A, Fernandez-Ranada JM. All-trans retinoic acid treatment and Sweet syndrome. Leukemia 1994;8:1596.

29 Cox NH, O'Brien HA. Sweet's syndrome associated with trans-retinoic acid treatment in acute promyelocytic leukaemia. Clin Exp Dermatol 1994;19:51-52.
30 Frankel S, Weiss M, Warrel Jr RP. A 'retinoic acid syndrome' in acute promyelocytic leukemia: reversal by corticosteroids. Blood 1991;78(Suppl):380a.

31 Paydas S, Yavuz S, Disel U, et al. Vasculitis associated with all trans retinoic acid (ATRA) in a case with acute promyelocytic leukemia. Leuk Lymphoma 2003;44: 547-548.

32 van der Vliet HJJ, Roberson AE, Hogan MC, et al. Alltrans-retinoic acid-induced myositis: a description of two patients. Am J Hematol 2000;63:94-98.

33 Piette WW, Trapp JF, O’Donnell MJ, et al. Acute neutrophilic dermatosis with myeloblastic infiltrate in a leukemia patient receiving all-trans-retinoic acid therapy. J Am Acad Dermatol 1994;30:293-297. 